\title{
Efektivitas Flat Design dalam Motion Graphic "Pentingnya Rating Usia Film Bagi Anak"
}

\author{
INKO SAKTI DEWANTO, DAFFA VIDI MULYADI
}

Program Studi Desain Komunikasi Visual, Institut Teknologi Nasional Bandung Email: inkosakti@itenas.ac.id

Received 26 Oktober2020 | Revised 20 November 2020 | Accepted 30 November 2020

\begin{abstract}
ABSTRAK
Aktivitas menonton film adalah salah satu bentuk hiburan bagi masyarakat, baik di bioskop maupun melalui kanal streaming online. Saat ke bioskop kadang kita melihat orang tua yang membawa anaknya menonton film yang tidak sesuai rating usianya. Hal tersebut tentu saja dapat memberikan dampak buruk bagi anak. Meskipun rating usia penonton film selalu tertera di tiap media promosinya, namun tetap saja masih sering ditemui orang tua yang acuh akan hal tersebut. Maka dari itu penelitian ini bertujuan untuk mendukung rancangan motion graphic tentang sosialisasi pentingnya rating film, khususnya untuk target para orang tua. Dengan menganalisa efektivitas karya motion graphic tersebut melalui pendekatan kualitatif, diharapkan dapat membantu para orang tua supaya lebih bijak dan selektif dalam memilih film untuk ditonton bersama anaknya di bioskop. Elemen visual yang menerapkan gaya flat design akan dianalisa menggunakan prinsip-prinsip motion graphic untuk menentukan efektivitasnya.
\end{abstract}

Kata kunci: motion graphic, rating usia film, flat design

\begin{abstract}
The activity of watching movies is a form of entertainment for the community, both in the cinema and through online streaming channels. When we go to the cinema, we sometimes see parents bringing their children to watch films that do not match their age rating. This of course can have bad impacts on children. Eventhough the age rating of film viewers is always listed in each of the promotional media, parents still often find it indifferent. Therefore, this study aims to support the design of motion graphics about the socialization of the film ratings importance, especially for the parents. By analyzing the effectiveness of motion graphic work through a qualitative approach, it is hoped that it can help parents to be wiser and more selective in choosing films to watch with their children in theaters. The visual elements that apply the flat design style will be analyzed using motion graphic principles to determine their effectiveness.
\end{abstract}

Keywords: motion graphic, film age-rating, flat design 


\section{PENDAHULUAN}

Menonton film merupakan salah satu aktivitas hiburan yang sudah berkembang sejak lama. Banyak sekali bentuk media yang dapat diakses jika kita ingin menonton film. Mulai layar lebar di bioskop, televisi, hingga kini di kanal-kanal streaming online yang sangat mudah diakses dari gawai yang kita miliki. Memang, menonton film di bioskop masih menjadi salah satu aktivitas yang digemari oleh banyak kalangan, khususnya di perkotaan. Menonton film di bioskop menghadirkan banyak sensasi, baik dari segi visual maupun audionya. Hal tersebutlah yang membuat aktivitas menonton film (terutama ke bioskop), menjadi salah satu hiburan yang digemari banyak orang, termasuk keluarga. Saat berada di bioskop, merupakan pemandangan umum bila kita melihat orang tua mengajak serta anak-anaknya menonton film.

Terlepas dari unsur hiburan tersebut terdapat aspek penting yang wajib menjadi perhatian bagi orang yang ingin menonton film, yaitu tentang batasan rating usia yang berlaku. Hal inilah yang masih sering diabaikan oleh para orang tua. Meskipun pada poster film sudah tertera dengan jelas rating usianya, namun peringatan batasan tersebut masih saja kurang efektif. Masih saja sering kita temui di ruang bioskop, suara-suara celoteh anak kecil di tengah film berlangsung, padahal film tersebut berkategori dewasa. Padahal dalam film berrating dewasa, terdapat banyak adegan kekerasan verbal maupun fisik, seks, obat-obatan terlarang, dan sebagainya yang tentu saja tidak cocok dikonsumsi anak di bawah (Ellora, 2018). Hal ini dikarenakan wawasan/informasi akan rating usia film yang masih belum utuh diserap oleh masyarakat, khususnya para orang tua.

L. R. Huesmann telah melakukan penelitian berjudul "The Impact of Electronic Media Violence: Scientific Theory and Research" yang dipublikasikan di Journal Adolesc Health (2007) . Berdasarkan hasil penelitiannya, anak-anak yang terpapar konten berbau kekerasan menimbulkan dampak jangka pendek dan panjang (Irfani, 2019). Dampak jangka pendek, konten kekerasan dapat merangsang anak-anak untuk meniru secara langsung aksi kekerasan yang mereka lihat. Sedangkan dampak jangka panjangnya, konten kekerasan mampu menyebabkan perubahan emosi pada anak-anak. Kesehatan mental anak pun bisa ikut terganggu jika terus menerus diajak ke bioskop dan sering menonton film yang tidak sesuai usianya.

Di Indonesia, rating film ditentukan oleh Lembaga Sensor Film (LSF). Sementara di Amerika Serikat, rating film ditentukan oleh Motion Pictures Association (MPA). Rating usia yang telah ditetapkan oleh kedua lembaga tersebut yang idealnya menjadi pedoman dan media informasi bagi masyarakat jika ingin mengetahui konten film yang bersangkutan. Melalui media motion graphic dengan gaya visual yang ringan (flat design), peneliti bertujuan menyampaikan wawasan akan rating usia film secara utuh kepada para orang tua, yang dilengkapi juga dengan etika membawa anak ke bioskop. Sehingga diharapkan anak dapat terhindar dari dampak-dampak negatif yang ditimbulkan karena menonton film yang tidak sesuai rating usianya (Nata dkk, 2018).

Penerapan gaya flat design pada motion graphic "Pentingnya Rating Usia Film Bagi Anak" mengacu pada sifatnya yang sederhana, lebih mudah dimengerti, dan informatif. Selain itu, flat design yang awalnya banyak digunakan pada platform digital (website dan mobile apps) memang memiliki tampilan visual yang cenderung minimalis, simpel, dengan mengandalkan warna-warna yang cerah dan kontras agar konten informasi/pesannya dapat dengan cepat dipahami oleh target audiens yang bersangkutan (Anindita dan Riyanti, 2016). Penelitian ini bertujuan untuk memudahkan para orang tua dalam memahami rating film, dampak yang 
ditimbulkan bila anak menonton film yang tidak sesuai usianya, serta mengedukasi tentang etika dan tips untuk orang tua yang ingin mengajak anaknya menonton film di bioskop.

\section{METODE PENELITIAN}

\subsection{Metode Pengumpulan Data}

Jenis data pada penelitian ini dikelompokkan ke dalam data primer dan data sekunder. Yang termasuk data primer yaitu antara lain kuesioner, wawancara, serta observasi. Sedangkan untuk data sekunder yang digunakan yaitu literatur-literatur pustaka, antara lain buku, artikel/jurnal ilmiah, dan juga beberapa artikel internet (Hardani dkk, 2020). Berikut ini detail penjelasan dari data yang sudah dihimpun.

\section{Kuesioner}

Menyebarkan kuesioner kepada target audiens yaitu para orang tua. Tujuannya untuk mengetahui presentase orang tua yang pernah membawa anaknya ke bioskop, seberapa paham mereka tentang rating usia film, apa alasan mereka membawa anaknya ke bioskop, serta bagaimana reaksi anaknya saat sedang menonton di dalam bioskop.

\section{Wawancara}

Narasumber utama untuk diwawancara pada penelitian ini yaitu Verty Sari Pusparini, S.Psi., M.Psi., seorang psikolog klinis anak dan remaja. Data yang digali terfokus untuk mengetahui dampak psikologi apa yang akan terjadi jika anak terus menerus menonton film yang tidak sesuai usianya.

\section{Observasi}

Observasi dilakukan di beberapa bioskop di Kota Bandung untuk mengamati orang tua yang membawa anaknya dan bagaimana reaksi anaknya ketika di dalam bioskop. Observasi yang dilakukan bersifat tersembunyi supaya tidak mengganggu kenyamanan penonton lainnya ketika menonton film.

\section{Literatur Pustaka}

Beberapa literatur pustaka utama yang digunakan yaitu antara lain "Exploring Motion graphics" oleh Rebecca Gallagher dan Andrea Moore Paldy (2006), "100 Tahun Bioskop di Indonesia (1900 - 2000)" karya M. Johan Tjasmadi (2008), serta "Motion Design: Moving Graphics for Television, Music Video, Cinema, and Digital Interfaces" oleh Matt Woolman (2004). Selain buku-buku tersebut, data sekunder juga disadur dari beberapa jurnal/artikel ilmiah yang mengangkat topik tentang motion graphic, flat design, serta perkembangan psikologi anak/balita.

\subsection{Metode Analisis}

Dalam sebuah karya motion graphic pasti memuat informasi penting untuk target audiensnya, yang terdiri atas susunan elemen grafis, tipografi, hingga audio yang terpadu (Gallagher \& Paldy, 2006). Perpaduan beberapa elemen tersebut haruslah disusun dengan terstruktur dengan didukung konten informasi yang komprehesif (informasi primer, sekunder, dan seterusnya). Susunan konten informasi itulah yang akan diterjemahkan dalam karya motion graphic utuh yang sesuai dengan prinsip-prinsipnya. Menurut Krasner (2008), berikut ini merupakan prinsip-prinsip dasar motion graphic, yang akan digunakan sebagai instrumen analisis dalam penelitian ini. 


\section{Composition}

Saat merancang komposisi desain, pasti melibatkan kelompok-kelompok elemen visual hingga menjadi sebuah tata letak tertentu. Beberapa jenis komposisi dalam motion graphic yaitu gathering, dispersion, exclusion, chunking, optical center, dan off-center. Semua jenis komposisi tersebut dapat menjadi acuan untuk membentuk komposisi yang estetis, serta dapat membuat tiap elemen visual yang terlibat menjadi saling berinteraksi. Sisi interaktif inilah yang menjadi daya tarik dalam karya motion graphic.

\section{Frame}

Umumnya, komposisi pada bingkai/frame terbentuk dari 4 sisi: kiri, kanan, atas, dan bawah. Bentuk dimensi frame tergantung oleh alat/gawai apa yang kita gunakan. Maka dari itu dibutuhkan pemahaman serta kepekaan khusus dalam mengolah elemen-elemen visual dalam sebuah frame, supaya pesan/konten dari motion graphic dapat tersampaikan dengan utuh kepada audiens.

\section{Flow}

Bila kita menonton sebuah motion graphic, pastinya mata akan membaca dan mengikuti pergerakan tertentu. Pergerakan tersebut akan membawa elemen-elemen visual di dalam frame yang akan memicu otak kita untuk dapat memahami pesan yang disampaikan secara bertahap.

\section{Transition}

Secara umum transisi merupakan efek/pola perpindahan dari satu frame ke frame selanjutnya. Banyak sekali jenis transisi yang bisa diimplementasikan, baik dalam video, film, animasi, dan juga motion graphic. Beberapa jenis transisi yang sering digunakan yaitu cut, dissolve, overlap, push, slide, wipe, glow, page turn, dan sebagainya.

\section{Texture}

Tekstur yang diaplikasikan pada elemen-elemen visual dapat menambahkan kesan dimensi, penekanan, kedalaman, dan pastinya meningkatkan aspek estetika pada sebuah karya desain.

\section{Sound}

Motion graphic termasuk ke dalam klasifikasi karya audio visual. Selain mengedepankan elemen visual yang bergerak, pastinya juga ditunjang oleh elemen suara/audio yang saling berkaitan. Bisa dibilang elemen suara adalah jiwanya, elemen visual adalah raganya. Detil efek suara terkecil pun mampu memberikan kesan/efek tersendiri bagi audiens.

\section{Emotion}

Karya yang baik selalu dapat diterima dengan baik oleh audiens. Tetapi karya yang hebat tidak hanya diterima saja, namun pasti dapat membuat audiens terpana, terheran, bahkan sulit untuk melupakannya. Hal-hal tersebut dapat dicapai oleh perancangnya, apabila mampu merumuskan konten yang mampu mengusik/menyentuh sisi emosi dari audiensnya.

\section{Inspiration}

Sulit di era sekarang untuk menemukan karya yang benar-benar orisinal. Dalam menemukan ide yang terbaik, pastinya akan ditunjang oleh referensi/inspirasi yang beragam pula. Hal inilah yang salah satunya akan menentukan keberhasilan karya yang dihasilkan. Bila sukses, karya tersebut akan dapat menjadi inspirasi baru bagi audiens. 


\section{HASIL DAN PEMBAHASAN}

\subsection{Motion graphic "Pentingnya Rating Usia Film Bagi Anak"}

a. Durasi: 6 menit 44 detik.

b. Dimensi: $1920 \times 1080$ pixel.

c. Penempatan: Youtube.

d. Konten:

Bagian Pertama, informasi tentang definisi dan klasifikasi rating film, serta data anak yang menonton film namun tidak sesuai rating usianya.

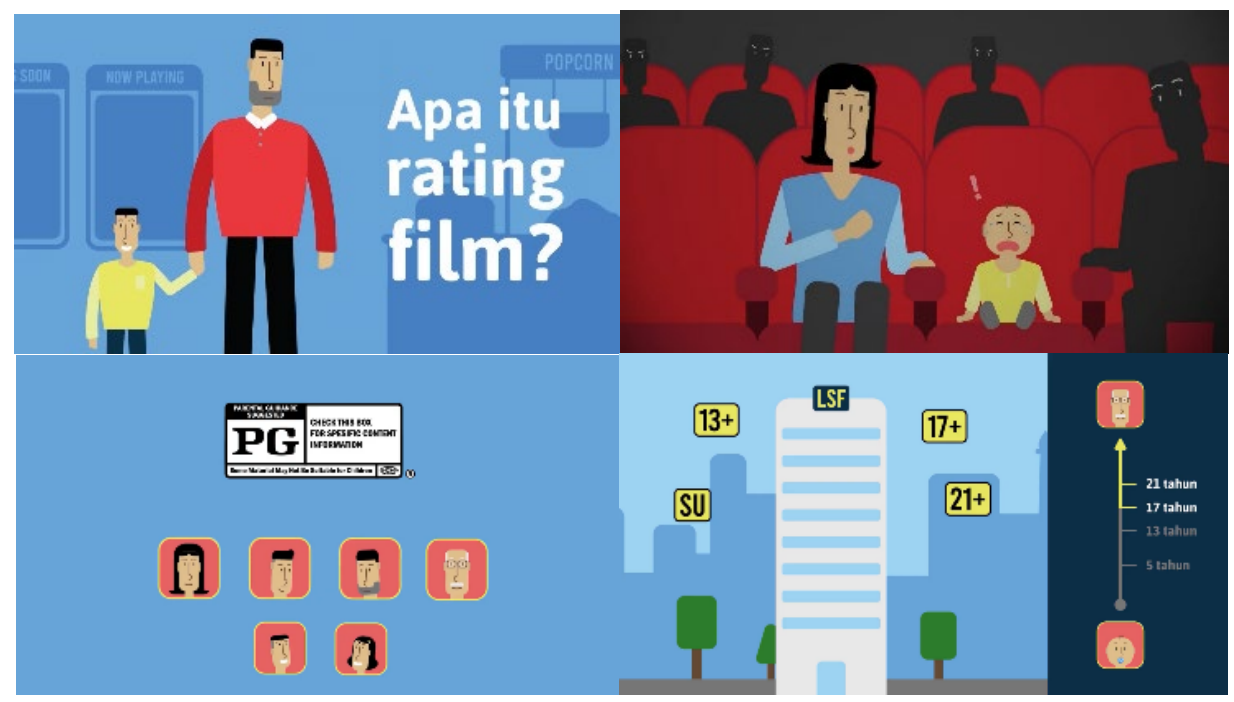

Gambar 1. Beberapa Cuplikan Konten Bagian Pertama

Bagian Kedua, dampak-dampak yang ditimbulkan jika anak menonton film yang tidak sesuai rating usia.

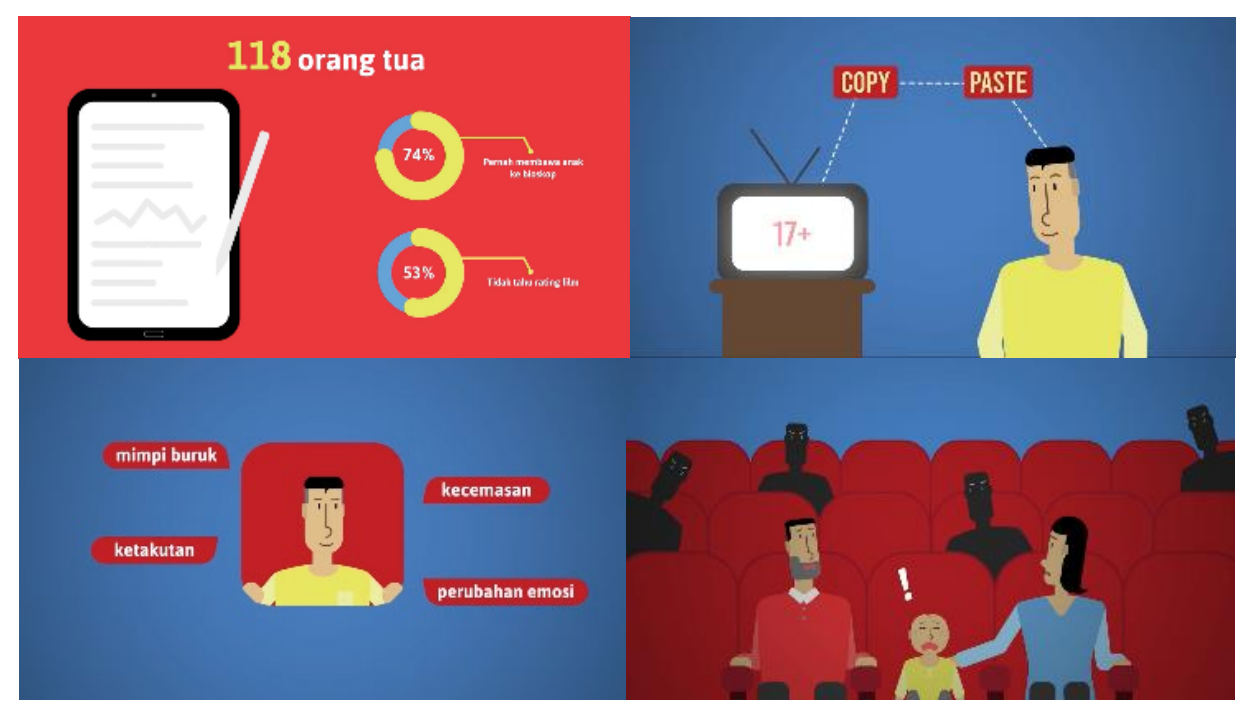

Gambar 2. Beberapa Cuplikan Konten Bagian Kedua

Bagian Ketiga, hal-hal yang harus diperhatikan/dihindari dan tips untuk orang tua jika ingin membawa anaknya ke bioskop. 


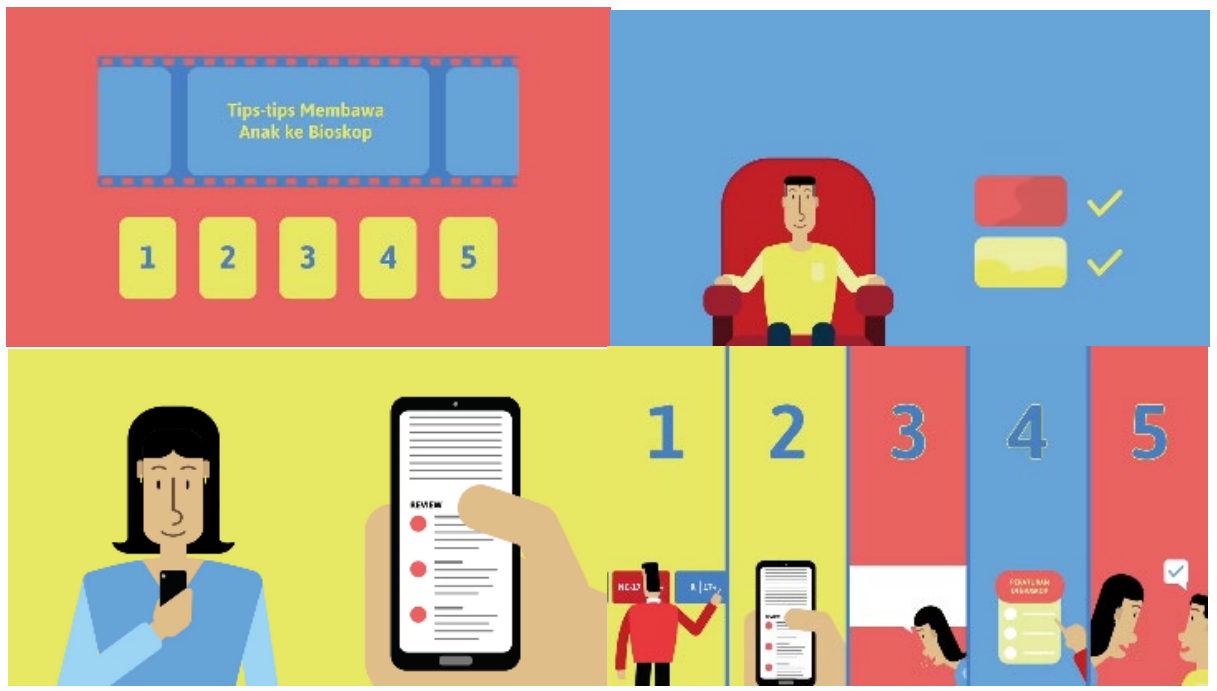

Gambar 3. Beberapa Cuplikan Konten Bagian Ketiga

\subsection{Efektivitas Flat Design pada Prinsip-Prinsip Motion graphic}

Gaya flat design telah menjadi tren dalam satu dasawarsa terakhir dan tetap bertahan karena tren media digital yang pesat. Hal tersebut karena konten visual yang sederhana menjadi syarat utama dalam menunjang efektivitas media. Aspek fungsionalitas dengan ditunjang tata letak yang bersih merupakan ciri khas dari flat design, yaitu tanpa bayangan, tekstur, tipografi Sans Serif, elemen grafis 2 dimensi yang datar/flat, hingga warna-warna cerah/tenang, dan banyak white space (Rustan, 2019). Melalui beberapa prinsip motion graphic berikut ini, akan dianalisa lebih mendalam tentang elemen-elemen visual yang terdapat pada beberapa sampel adegan.

\section{Composition}

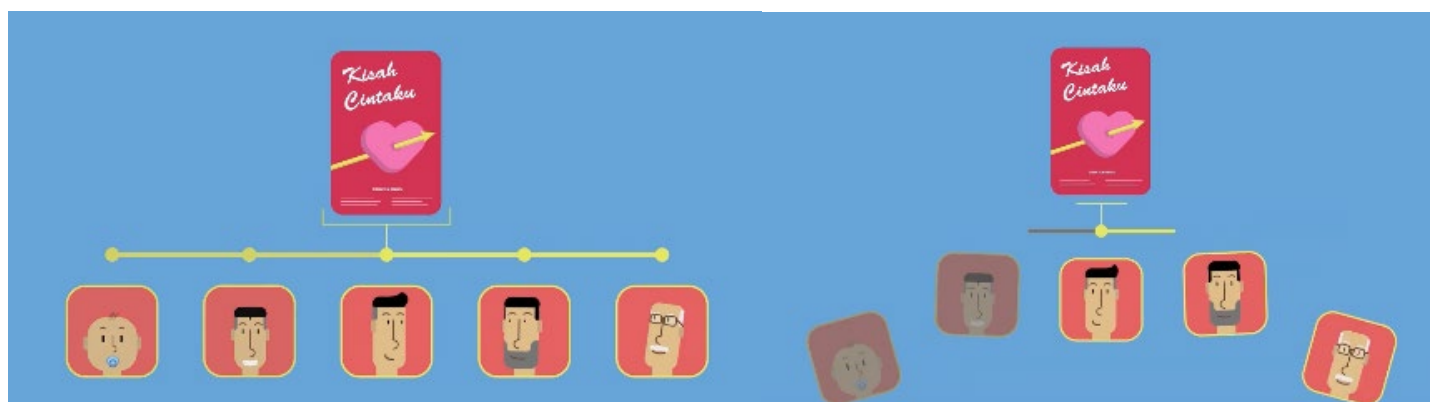

Gambar 4. Beberapa Cuplikan Yang Menerapkan Komposisi Jenis Gathering (Kiri) Dan Dispersion (Kanan)

Pada contoh cuplikan di atas, perancang menerapkan 2 jenis komposisi. Pertama yaitu gathering, di mana semua elemen visual sengaja dikelompokkan dalam 1 area/kuadran tertentu. Setelahnya, adegan berubah sehingga tokoh-tokoh nampak berjatuhan tidak beraturan. Hal ini termasuk ke dalam jenis dispersion, di mana audiens akan diajak untuk tetap menemukan titik fokus pada komposisi yang nampak kacau/tidak teratur. Titik fokus tersebut adalah poster film "Kisah Cintaku" yang menjadi fokus pembahasan mengenai target usia penontonnya yang pantas. 


\section{Frame}

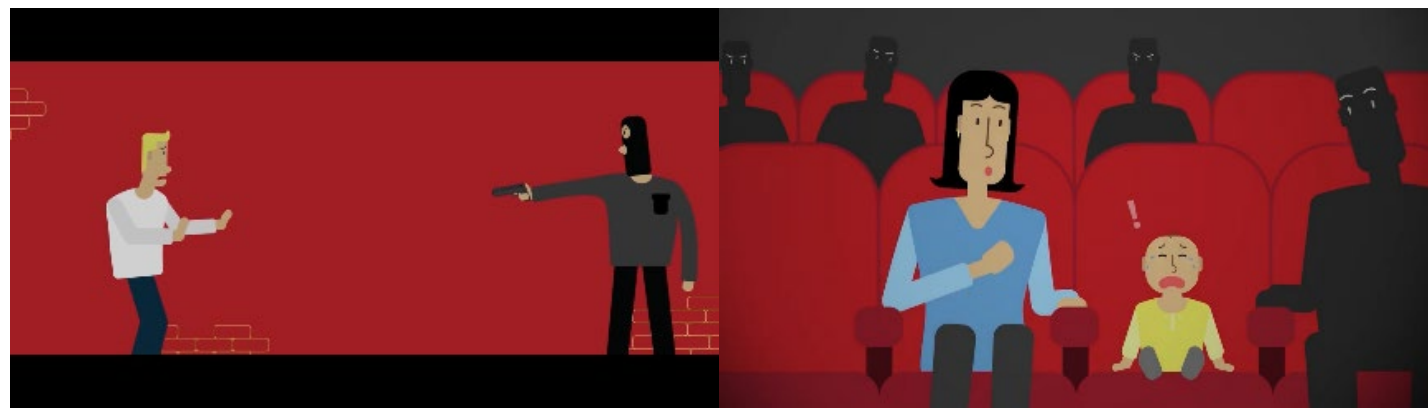

Gambar 5. Cuplikan Tentang Pengaturan Elemen Visual (Tokoh) Dalam Frame Adegan

Pada adegan penjahat menodongkan pistol, nampak jelas ada bagian hitam di bagian atas dan bawah frame. Hal tersebut jelas untuk menegaskan tentang adegan sebuah film yang memiliki dimensi umum frame layar 16:9. Adegan selanjutnya menunjukkan seorang balita yang menangis di tengah adegan film. Di situ nampak jelas perbandingan margin kiri, kanan, atas, bawah yang seimbang untuk menjadikan tokoh ibu dan balitanya sebagai fokus utama.

\section{Flow}

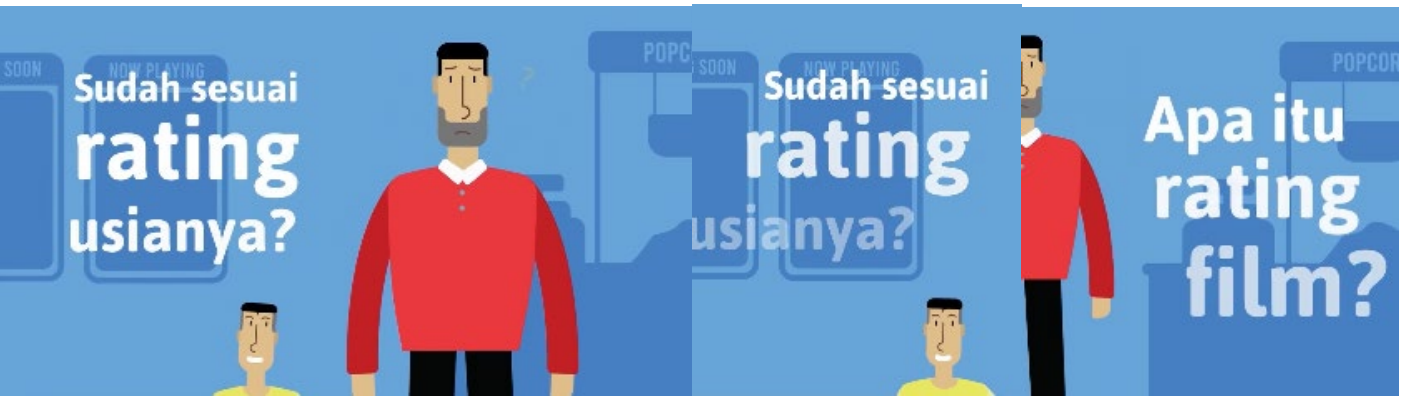

Gambar 6. Cuplikan Tentang Flow Pergerakan Tipografi Sebelumnya (Kiri Dan Tengah) Menuju Pergerakan Tipografi Selanjutnya (Kanan)

Adegan tersebut menunjukkan pertanyaan utama pada karya motion ini yang sesuai dengan judulnya. Mata kita otomatis pasti mengikuti gerakan tipografinya dibanding tokoh ayah dan anak, karena pikiran kita secara perlahan ingin memahami pesan/konten yang disampaikan di adegan tersebut.

\section{Transition}

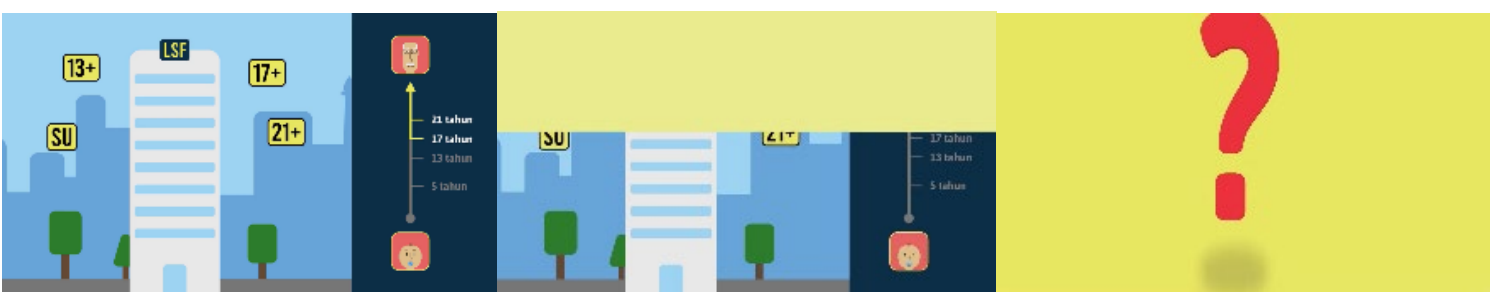

Gambar 7. Cuplikan Tentang Implementasi Transisi Push Down

Cuplikan di atas menunjukkan sebuah transisi sederhana (push down) yang seringkali digunakan. Dengan elemen visual yang flat, akan turut mempercepat transisi serta keterserapan informasi yang disampaikan. Nampak jelas bagaimana adegan berpindah ditandai dengan turunnya bidang kuning hingga memenuhi frame seutuhnya, menggantikan 
adegan sebelumnya. Semakin sederhana/simpel elemen visual yang digunakan, maka akan semakin mudah pula dalam menerapkan jenis transisi apa pun itu.

\section{Sound}

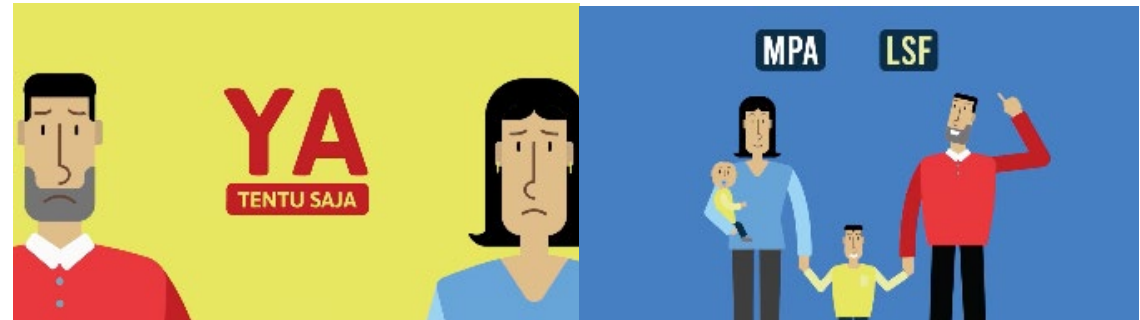

Gambar 8. Cuplikan adegan di Bagian Kedua (kiri) dan Bagian Ketiga (kanan)

Dua sampel adegan di atas merupakan cuplikan adegan yang berada di segmen/bagian yang berbeda. Di sebelah kiri tempo musik mendadak berubah menjadi lebih lambat, instrumental yang minimalis dengan nada-nada minor untuk mendukung raut wajah orang tua yang nampak khawatir dan was-was. Sedangkan di sebelah kanan tempo musik latar lebih sedikit upbeat dengan iringan orkestra sederhana, menunjukkan bahwa sudah akan mencapai penutup dari motion graphic ini.

\section{Emotion}
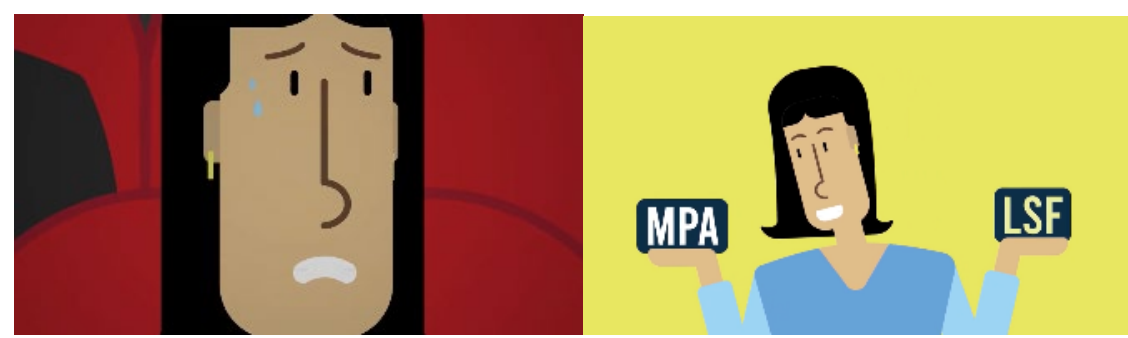

Gambar 9. Cuplikan Dua Adegan Dengan Menonjolkan Sisi Emosi Yang Kontras

Meskipun flat design memiliki ciri khas elemen visual 2D yang sederhana, namun bukan berarti dari segi konten juga datar-datar saja alias monoton. Dari aspek karakter vektor yang dirancang masih sangat memungkinkan untuk menonjolkan ekspresi, gestur, dan gerakan yang mampu mengangkat mood adegannya. Seperti beberapa contoh cuplikan di atas. Ekspresi gugup, khawatir, was-was masih nampak jelas di raut wajah karakternya, meskipun desainnya sederhana. Begitu juga dengan adegan sebelahnya, ekspresi serta gestur yang cenderung ceria dan rileks masih bisa ditangkap dengan mudah oleh audiens. Di sinilah letak tantangan sebuah motion graphic. Dengan visual yang sesederhana mungkin, namun harus tetap "hidup" dan lebih jauh lagi dapat tertancap di ingatan audiens. 


\section{Inspiration}

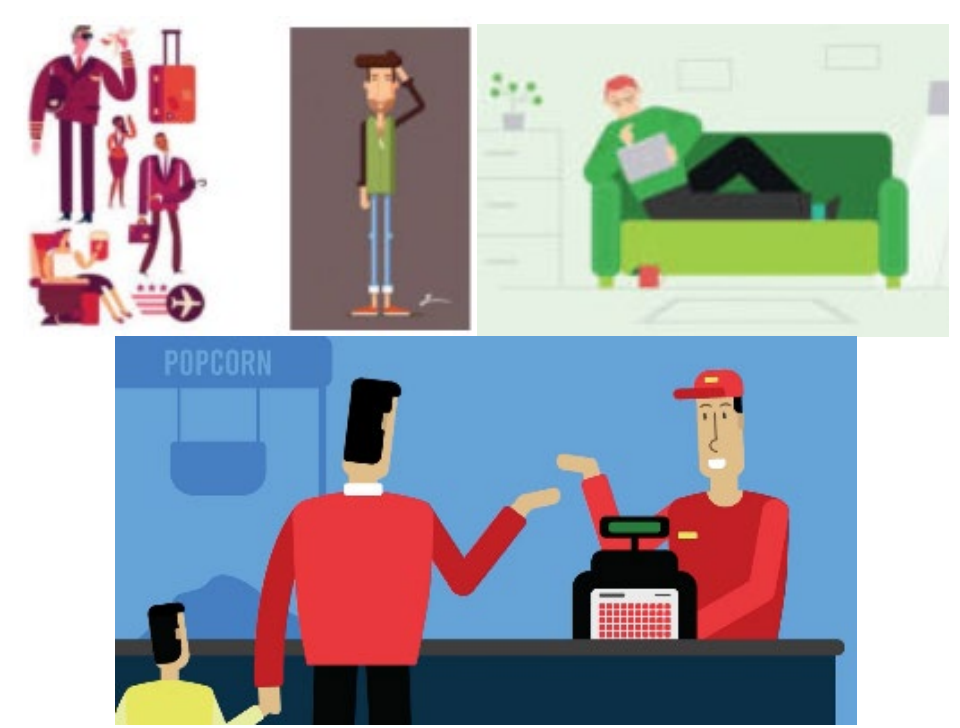

Gambar 10. Sampel Inspirasi Gaya Flat Design (Atas) Serta Implementasinya Pada Karya Motion Graphic Ini (Bawah)

Banyak sekali referensi gaya flat design yang dapat ditemukan. Salah satu tahapan penting dalam mendesain yaitu si desainer idealnya memiliki referensi/inspirasi, supaya bisa lebih mudah dalam mengembangkan gaya khas desainnya sendiri. Dari gambar di atas dapat dilihat bahwa proses mencari ide dari sumber inspirasi terbukti memang dibutuhkan. Dengan gaya flat design yang sedemikian rupa, desainer diharapkan mampu menyampaikan konten secara efektif dengan pendekatan yang tepat untuk target audiensnya.

\section{KESIMPULAN}

Semakin banyak tontonan film yang bisa semakin mudah kita akses. Selain menonton di bioskop, layanan streaming online kini juga sudah semakin memanjakan penggemar film. Sebelum pergi menonton ke bioskop sebaiknya kita mengecek dulu rating usia yang ditujukan oleh film yang bersangkutan. Apalagi kalau kita sudah memiliki anak, hal tersebut wajib dilakukan untuk memfilter konten/hal yang akan dikonsumsi oleh si anak. Melalui media motion graphic "Pentingnya Rating Usia Film Bagi Anak", wawasan mengenai rating usia film dapat dikemas dengan utuh dan didukung oleh elemen visual serta audio yang terpadu. Gaya flat design yang tetap bertahan hingga sekarang, sangatlah tepat diterapkan dalam karya motion graphic ini. Setelah membedah beberapa sampel cuplikan secara terperinci menggunakan prinsip-prinsip motion graphic, gaya flat design memang efektif dan sangat ideal untuk menyampaikan konten tentang rating usia film kepada target audiens orang tua muda. Keseharian para orang tua masa kini yang sulit terlepas dari gawainya, (yang notabene didominasi elemen visual dengan gaya flat design) akan semakin mempercepat proses pemahaman mereka tentang betapa pentingnya rating usia film bagi anak.

\section{DAFTAR RUJUKAN}

Anindita, M. \& Riyanti, Menul T. (2016). Tren Flat Design Dalam Desain Komunikasi Visual. Jurnal Dimensi DKV Seni Rupa dan Desain, 1-14. 
Ellora, D. (2018, Juli 14). Membawa Bayi ke Bioskop, Bolehkah? Diambil kembali dari Beauty Journal by Sociolla: https://journal.sociolla.com/lifestyle/membawa-bayi-ke-bioskop

Gallagher, R., \& Paldy, A. M. (2006). Exploring Motion graphics. New York: Delmar Cengage Learning.

Hardani, dkk (2020). Metode Penelitian Kualitatif \& Kuantitatif. Yogyakarta: Pustaka Ilmu.

Huesmann, L. R. (2017). The Impact of Electronic Media Violence: Scientific Theory and Research. Journal of Adolescent Health, S6-S13.

Irfani, F. (2019, Oktober 10). Orang Tua Perlu Tahu: Joker Bukan Avengers yang Bisa Ditonton Anak. Diambil kembali dari Tirto.id: https://tirto.id/orangtua-perlu-tahujoker-bukan-avengers-yang-bisa-ditonton-anak-ejre

Krasner, J. (2008). Motion graphic Design : Applied History and Aesthetics. Massachusetts: Focal Press.

Nata, V. F., dkk (2016). Perancangan Video Motion graphic Tentang Pentingnya Rating Dalam Video Game Bagi Orang Tua. Jurnal DKV Adiwarna, 1-2.

Rustan, S. (2019, Juli 17). FLAT DESIGN. Diambil kembali dari suriantorustan.com: https://www.suriantorustan.com/flat-design/

Tjasmadi, H. J. (2008). 100 Tahun Bioskop di Indonesia (1900 - 2000). Jakarta: PT. Megindo Tunggal Sejahtera.

Woolman, M. (2004). Motion Design: Moving Graphics for Television, Music Video, Cinema, and Digital Interfaces. Brighton \& Hove: Rotovision. 